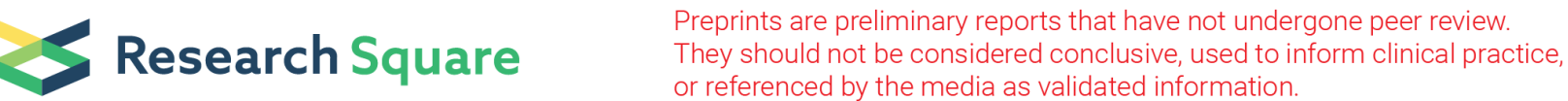

\section{Strengthen Luteal Phase Support for the Patients With Low Serum Progesterone on the Day of Embryo Transfer in Artificial Endometrial Preparation Cycles: a Large-sample Retrospective Trial}

\section{Hongyuan Gao}

Shanghai Ninth People's Hospital

Jing Ye

Shanghai Ninth People's Hospital

Hongjuan Ye

Shanghai East Hospital

\section{Qingqing Hong}

Shanghai Ninth People's Hospital

\section{Lihua Sun}

Shanghai East hospital

Qiuju Chen ( $\nabla$ chenqj75@126.com )

Shanghai Ninth People's Hospital https://orcid.org/0000-0001-7635-4401

\section{Research}

Keywords: artificial endometrium preparation cycles, progesterone, luteal phase support, clinical pregnancy, live birth

Posted Date: December 28th, 2020

DOl: https://doi.org/10.21203/rs.3.rs-134070/v1

License: (c) (i) This work is licensed under a Creative Commons Attribution 4.0 International License. Read Full License

Version of Record: A version of this preprint was published at Reproductive Biology and Endocrinology on April 23rd, 2021. See the published version at https://doi.org/10.1186/s12958-021-00747-8. 


\section{Abstract}

Background: The low serum progesterone (P) on the day of frozen embryo transfer (FET) is associated with diminished pregnancy rates in artificial endometrium preparation cycles using vaginal micronized $P$, but it is no consensus whether the strengthened luteal phase support (LPS) for the patients with low P on the FET day in artificial cycles is beneficial. A single centric, large-sample retrospective trial was aimed to investigate the contribution of strengthened LPS to the pregnancy outcomes for the groups of low $P$ levels on the FET day in artificial endometrium preparation cycles.

Methods: Women who had undergone first artificial cycle for endometrium preparation after freeze-all in our clinic during 2016 and 2018 were classified into two groups depending on the serum P levels on the FET day, routine LPS was administered for group $B(P \geq 10.0 \mathrm{ng} / \mathrm{ml}$ on the FET day, $\mathrm{n}=1261)$ and strengthened LPS (routine LPS+ im P 40mg daily) for group A ( $P<10.0 \mathrm{ng} / \mathrm{ml}$ on the FET day, $\mathrm{n}=1295)$, the primary endpoint was the live birth rate and secondary endpoints were clinical pregnancy, miscarriage and neonatal outcomes.

Results: The results showed the clinical pregnancy rate in group A was lower than group B $(48.4 \%$ vs $53.2 \%$, aRR $0.81,95 \% \mathrm{Cl} 0.68,0.96)$, the miscarriage rate was similar between the two groups $(16.0 \%$ vs $14.7 \%$, aRR $1.09,95 \% \mathrm{Cl} 0.77,1.54)$. The live birth rate was slightly lower than group B $(39.5 \%$ vs $43.3 \%$, aRR $0.84,95 \% \mathrm{Cl} 0.70,1.0)$. The birthweights and other neonatal outcomes were found no difference between the two groups $(P>0.05)$.

Conclusions: The strengthened LPS for the section of patients of low P levels on the FET day might help to have a reasonable pregnancy outcome, although the live birth rate was slightly lower than the groups with normal serum $\mathrm{P}$ levels on the FET day and usage of routine LPS.

Trial registration: no available.

\section{Introduction}

Nearly 5 million babies have been delivered following assisted conception (IVF/ICSI) and the demand is increasing. Meticulous ovarian stimulation and well programmed luteal phase support (LPS) are the landmarks of treatment success. Although the importance of LPS in IVF/ICSI cycles is well established, the optimal route, dose and duration of this support is still a matter of debate [1]. Artificial endometrial preparation for frozen embryo transfer (FET) cycle is different from stimulated IVF cycle in that there is no endogenous progesterone $(P)$ production, therefore instead of luteal phase supplementation, there is a need for luteal phase "creation" or replacement [2]. In the context, artificial cycles provide us a chance to explore the optimal $\mathrm{P}$ amount for supporting embryo implantation without the interferences with endogenous $\mathrm{P}$ in stimulation cycles [3].

P administration for LPS has multiple routes including oral, intramuscular, vaginal and rectal routes. Oral route undergoes extensive first-pass metabolism which limits its efficacy for luteal support. Vaginal 
administration is preferred over intramuscular injection for its uterine first-pass effect, its convenience and good tolerability [3]. However, body mass index (BMI) and vaginal environment affect serum levels after vaginal route, the serum $P$ concentrations show a marked inter-individual difference despite the similar dose of $\mathrm{P}$ administration by vaginal route [4]. Low serum $\mathrm{P}$ levels on the FET day in artificial cycles using vaginal $P$ have been reported to be associated with poorer reproductive outcomes [5-7], however, it is no consensus whether the strengthened LPS is beneficial for the patients with low P levels in artificial cycles $[8,9]$. The debate of using one-size-fit-all regimen or individualized protocols in artificial endometrial preparation cycles has still continued.

In our clinic, the serum P levels on the FET day was routinely monitored in artificial endometrium preparation cycles, and for the cases with low P levels $(<10.0 \mathrm{ng} / \mathrm{ml})$ on the FET day, we added intramuscular P $40 \mathrm{mg}$ daily to salvage the FET cycles. Aimed to investigate the contribution of strengthened LPS for the women of low P levels on the FET day, we performed a single centric, largesample retrospective trial to compare the pregnancy outcomes of artificial cycles between the two treatments.

\section{Methods}

\section{Study design and population}

A retrospective study was conducted at the Department of Assisted Reproduction of the Ninth People's Hospital of Shanghai Jiao Tong University School of Medicine. Women who had undergone first artificial cycle for endometrium preparation in a freeze-all policy during the period from January 2016 to December 2018 were enrolled. Exclusion criteria were as follows: patients older than 42 years of age, a history of recurrent miscarriages or recurrent implantation failure (e.g. unsuccessful transfer of $\geq 3$ times), with systemic diseases, uterine diseases (e.g. fibroids and congenital uterine malformation) or hydrosalpinx. The cycles without measuring serum $\mathrm{P}$ levels on the FET day were excluded. Only the first artificial cycle in our clinic was included for each patient, although some patients had previous FET failures elsewhere.

This study protocol was approved by the ethical committee of the hospital and was carried out in accordance with the Helsinki Declaration. Due to the retrospective nature, informed consent was not required and patients' data were used anonymously.

\section{Frozen embryo transfer and luteal phase support}

For endometrium preparation in FET cycles, oral $17 \beta$-estradiol (Fematon red tablets $4 \mathrm{mg}$, twice daily; Abbott Healthcare Products B.V.) or ethiny oestradiol 25 ug three times daily was commenced on the third day of a natural or progesterone withdrawal menstrual cycle. After 12-14 days, vaginal ultrasound examination was performed, when the endometrial thickness reached $\geq 7 \mathrm{~mm}$, ultrasound detected quiescent ovaries and serum $P$ level was $<1.0 \mathrm{ng} / \mathrm{ml}, \mathrm{P}$ transformation was initiated using fematon yellow tablets (containing estradiol $4 \mathrm{mg}$ and dydrogesterone $20 \mathrm{mg}$ twice daily, Abbott Healthcare 
Products B.V) and vaginal micronized progesterone capsule 200mg twice daily (Utrogestan, Laboratoires Besins International, France). Embryo transfer was performed 3 days after $\mathrm{P}$ administration for cleavagestage embryos or 5 days later for blastocyst transfer.

All patients completed the serum hormone examination of $P$ and estradiol at 8:00-9:00 of transfer day, and the last dose before FET was administered on the morning of the FET day. The vitrified-warmed embryo transfers were arranged at 13:30-15:30. Based on the serum P levels of the FET day, patients were classified into the two groups. For the cases with the serum $P$ levels $\geq 10.0 \mathrm{ng} / \mathrm{ml}$, the mentioned luteal phase support of dydrogesterone and vaginal P continued to use (Group B: normal P+ routine LPS). For the cases with the serum $P$ levels $<10.0 \mathrm{ng} / \mathrm{ml}$, the intramuscular $\mathrm{P} 40 \mathrm{mg}$ daily was added to strengthen luteal phase support after FET (Group A: low P+ strengthened LPS). LPS was stopped if the serum hCG test was negative on the $14^{\text {th }}$ day after FET. If the serum $\mathrm{hCG}$ test was positive, the LPS was continued to 10 weeks of gestation.

\section{Embryo quality assessment and vitrification}

The ovarian stimulation regimen included the $\mathrm{GnRH}$ antagonist protocol, $\mathrm{GnRH}$ agonist long protocol and progestin-primed ovarian stimulation. The embryo morphology assessment was evaluated on day 3, 5 and 6 after oocyte retrieval. Cleavage-stage embryos with at least 7 blastomeres and fragmentation $<20 \%$ were regarded as high-quality embryos. Blastocysts were scored according to the Gardner and Schoolcraft grading system [10] and recorded as high quality if they reached at least an expansion stage 3 with $\mathrm{A}$ or $\mathrm{B}$ for inner cell mass and trophectoderm (3BB). In all FET cycles, up to 2 embryos can be transferred. The vitrification and thawing procedure were previously described by Kuwayama et al [11]. Briefly, embryo vitrification was carried out via a Cyrotop carrier system, in combination with DMSO-EG-S as cryoprotectants. For thawing, embryos were transferred into dilution solution in a sequential manner.

\section{Outcome parameters and statistical methods}

The primary outcome of the study was the live birth rate. Secondary endpoints included rates of implantation, biochemical pregnancy, clinical pregnancy, miscarriage and perinatal outcomes. Live birth was defined as a live neonate born after 24 weeks of gestation. A clinical pregnancy was confirmed by the observation of a gestational sac on ultrasound scanning 4-5 weeks after embryo transfer. Miscarriage rate was defined as a loss of clinical pregnancy before the 24th gestational week. The implantation rate was calculated as the number of gestational sacs visualized on ultrasound examination divided by the number of embryos transferred. All calculations were made on a per transfer cycle.

Low birth weight and macrosomia were defined as birth weights $<2500 \mathrm{~g}$ and $\geq 4000 \mathrm{~g}$, respectively. Preterm birth was defined as a delivery before complete 37 gestational weeks. Pregnancy-related complications included gestational diabetes, intrahepatic cholestasis of pregnancy, pregnancy-induced hypertension and pre-eclampsia. All neonatal and delivery information were obtained from medical records or telephone interview by a trained nurse. 
The baseline characteristics and associated clinical outcomes were compared via $t$ test or chi-square test where appropriate. A multivariate logistic regression analysis was performed to determine the independent effect of serum $P$ on reproductive outcomes after adjustment for possible confounding factors, including maternal age, BMI (underweight, normal weight, overweight and obesity), infertility duration, gravidity, parity, infertility cause (tubal, PCOS, male, endometriosis and other), previous IVF failures, number and stage of embryos transferred. We analyzed the pregnancy outcomes for the groups to evaluate the effects of strengthened LPS for the group with the low serum P on the FET day.

All statistical analyses were performed with the use of the Statistical Package for Social Sciences (SPSS) version 21.0. A $P$ value of $<0.05$ was considered to be statistically significant difference.

\section{Results}

A total of 7674 artificial endometrium preparation cycles were screened and 2556 cycles met the inclusion criteria and underwent first artificial cycle for FET during the study period. Mean female age was $31.3 \pm 3.5$ years, BMI was $21.76 \pm 3.13 \mathrm{~kg} / \mathrm{m}^{2}$. The median estradiol levels on the FET day in artificial cycles were $210.0 \mathrm{pg} / \mathrm{ml}$ (interquartile range $116.0 \mathrm{pg} / \mathrm{ml}$ ). The median P levels on the FET day in artificial cycles were $9.9 \mathrm{ng} / \mathrm{ml}$ (interquartile range $4.2 \mathrm{ng} / \mathrm{ml}$ ). A total of 1261 women (49.3\%) with serum $P \geq 10.0 \mathrm{ng} / \mathrm{ml}$ on the FET day received routine LPS (group B). A total of 1295 women (50.7\%) were recorded with serum $P<10.0 \mathrm{ng} / \mathrm{ml}$ on the FET day, then added intramuscular $\mathrm{P} 40 \mathrm{mg}$ daily from the FET day onwards, and they were classified into group $A$.

A flow diagram of the patient selection process is shown in Fig. 1. Baseline characteristics between the two groups are presented in Table 1. Women with group A were similar with group B in terms of age, infertility duration, gravity, parity, endometrium thickness, the number and stage of embryos transferred. In group $\mathrm{A}$, the BMI and AFCs were significantly higher $(P<0.05)$, and the basal FSH levels were slightly lower than group $\mathrm{B}(P<0.05)$. Compared with the control, women in group $\mathrm{A}$ had more frequently experienced obesity ( $7.2 \%$ vs $4.6 \%)$, less proportion of underweights $(9.4 \%$ vs $13.6 \%)$ and slightly higher proportion of PCOS $(17.2 \%$ vs $13.6 \%, P<0.05)$. 
Table 1

The basic characteristics of the population

\begin{tabular}{|c|c|c|c|}
\hline & $\begin{array}{l}\text { Low } P+\text { advanced LPS } \\
\text { (Group A, } n=1295 \text { ) }\end{array}$ & $\begin{array}{l}\text { Normal } P+\text { routine LPS } \\
\text { (Group B, } n=1261 \text { ) }\end{array}$ & P value \\
\hline Age (years) & $31.3 \pm 3.5$ & $31.4 \pm 3.5$ & 0.486 \\
\hline $\mathrm{BMI}\left(\mathrm{kg} / \mathrm{m}^{2}\right)$ & $22.11 \pm 3.26$ & $21.76 \pm 3.13$ & 0.005 \\
\hline Underweight $\left(<18.5 \mathrm{~kg} / \mathrm{m}^{2}\right)$ & $121(9.4 \%)$ & $170(13.6 \%)$ & \\
\hline Normal weight $\left(18.5-22.9 \mathrm{~kg} / \mathrm{m}^{2}\right)$ & $733(57.0 \%)$ & $690(55.2 \%)$ & \\
\hline Overweight (22.9-27.4 kg/m²) & $339(26.4 \%)$ & $332(26.6 \%)$ & \\
\hline Obesity (>27.5 kg/m²) & $92(7.2 \%)$ & $57(4.6 \%)$ & \\
\hline Infertility duration (yrs) & $2.9 \pm 2.7$ & $2.9 \pm 2.6$ & 0.584 \\
\hline Basal FSH (mIU/ml) & $5.61 \pm 1.39$ & $5.74 \pm 1.43$ & 0.017 \\
\hline Antral follicle counts & $14.6 \pm 7.7$ & $13.6 \pm 6.8$ & 0.002 \\
\hline Gravidity & & & 0.072 \\
\hline 0 & $735(56.8 \%)$ & $671(53.2 \%)$ & \\
\hline$\geq 1$ & $560(43.2 \%)$ & $590(46.8 \%)$ & \\
\hline Parity & & & 0.413 \\
\hline 0 & $1216(93.9 \%)$ & 1174(93.1\%) & \\
\hline$\geq 1$ & $79(6.1 \%)$ & $87(6.9 \%)$ & \\
\hline Infertility causes & & & 0.123 \\
\hline Tubal & $735(56.8 \%)$ & $768(60.9 \%)$ & \\
\hline Pcos & $223(17.2 \%)$ & $172(13.6 \%)$ & \\
\hline Male & $124(9.6 \%)$ & $118(9.4 \%)$ & \\
\hline Endometriosis & $36(2.8 \%)$ & $35(2.8 \%)$ & \\
\hline Other & $177(13.7 \%)$ & $168(13.3 \%)$ & \\
\hline Previous IVF failures & & & 0.427 \\
\hline 0 & $1114(86.2 \%)$ & 1104(87.5\%) & \\
\hline $1-2$ & $67(5.2 \%)$ & $53(4.2 \%)$ & \\
\hline$\geq 3$ & $114(8.8 \%)$ & $104(8.2 \%)$ & \\
\hline
\end{tabular}




\begin{tabular}{|llll|}
\hline & $\begin{array}{l}\text { Low P+advanced LPS } \\
\text { (Group A, n = 1295) }\end{array}$ & $\begin{array}{l}\text { Normal P+ routine LPS } \\
\text { (Group B, n = 1261) }\end{array}$ & P value \\
\hline $\begin{array}{l}\text { Serum estrogen on FET day }(\mathrm{pg} / \mathrm{ml}) \\
\text { median (IQR) }\end{array}$ & $203.0(112.0)$ & $216.0(123.5)$ & 0.082 \\
\hline $\begin{array}{l}\text { Serum P on FET day }(\mathrm{ng} / \mathrm{ml}) \\
\text { median (IQR) }\end{array}$ & $6.8(2.3)$ & $12.2(3.4)$ & $<0.001$ \\
\hline Endometrium thickness $(\mathrm{mm})$ & $9.82 \pm 1.84$ & & 0.993 \\
\hline Number of embryos transferred & & $9.82 \pm 1.88$ & 0.063 \\
\hline Single & $306(23.6 \%)$ & $254(20.1 \%)$ & 0.109 \\
\hline Double & $989(76.4 \%)$ & $1007(79.8 \%)$ & \\
\hline Embryo stage & & & $1020(80.9 \%)$ \\
\hline Cleavage & $1079(83.3 \%)$ & $241(19.1 \%)$ & \\
\hline Blastocyst & $216(16.7 \%)$ & & \\
\hline
\end{tabular}

The multinomial logistic analysis, done to predict serum $P<10.0 \mathrm{ng} / \mathrm{ml}$ on the FET day, including all meaningful clinical parameters (age, BMI, basal FSH levels and infertility causes), showed that only BMI was negatively related with serum $P$ on the FET day in artificial cycles $(P<0.05)$, mainly the subgroup of underweight $\left(\mathrm{BMI}<18.5 \mathrm{~kg} / \mathrm{m}^{2}\right)$ had a lower risk for low $\mathrm{P}(\mathrm{RR} 0.68,95 \% \mathrm{Cl} 0.52,0.88)$ while subgroup of obesity $\left(\mathrm{BMI}>27.5 \mathrm{~kg} / \mathrm{m}^{2}\right)$ did not reach the significance of increased risk for low $\mathrm{P}(\mathrm{RR} 1.36,95 \% \mathrm{Cl}$ $0.95,1.94)$.

\section{Implantation and pregnancy outcome}

Pregnancy outcomes in the two groups are shown in Table 2. The clinical pregnancy rate in group A was lower than that in group B (48.4\% vs $53.2 \%$, adjusted RR $0.81,95 \% \mathrm{Cl} 0.68-0.96)$, with a difference between groups of $4.8 \%$. The implantation rate was respectively $35.11 \%$ and $36.8 \%$ in group $A$ and $B$ (Crude RR $0.93,95 \% \mathrm{Cl} 0.82-1.05, \mathrm{P}=0.051$ ). The miscarriage in group $\mathrm{A}$ was similar with that in group $\mathrm{B}$ (16.0\% vs $14.7 \%$, adjusted RR $1.09,95 \% \mathrm{Cl} 0.77-1.54)$. The live birth rate in group $A$ was slightly lower than that in group $\mathrm{B}(39.5 \%$ vs $43.3 \%$, adjusted RR $0.84,95 \% \mathrm{Cl} 0.70-1.0)$. 
Table 2

The pregnancy outcomes in artificial FET cycles using strengthened luteal phase support

\begin{tabular}{|c|c|c|c|c|c|}
\hline & $\begin{array}{l}\text { Low P+ } \\
\text { strengthened } \\
\text { LPS } \\
\text { (Group A, } n= \\
\text { 1295) }\end{array}$ & $\begin{array}{l}\text { Normal P+ } \\
\text { routine LPS } \\
\text { (Group B, } n= \\
1261)\end{array}$ & $\begin{array}{l}\text { Crude RR } \\
(95 \% \mathrm{Cl})\end{array}$ & $\begin{array}{l}\text { Adjusted RR } \\
(95 \% \mathrm{Cl})\end{array}$ & $\begin{array}{l}P \\
\text { value }\end{array}$ \\
\hline $\begin{array}{l}\text { Biochemical } \\
\text { pregnancy rate }\end{array}$ & $\begin{array}{l}52.5 \% \\
(680 / 1295)\end{array}$ & $\begin{array}{l}58.1 \% \\
(733 / 1261)\end{array}$ & $0.80(0.68,0.93)$ & $0.80(0.67 .0 .96)$ & 0.014 \\
\hline $\begin{array}{l}\text { Clinical } \\
\text { pregnancy rate }\end{array}$ & $\begin{array}{l}48.4 \% \\
(627 / 1295)\end{array}$ & $\begin{array}{l}53.2 \% \\
(671 / 1261)\end{array}$ & $0.91(0.84,0.98)$ & $0.81(0.68,0.96)$ & 0.016 \\
\hline $\begin{array}{l}\text { Multiple } \\
\text { pregnancy rate }\end{array}$ & $\begin{array}{l}24.9 \% \\
(186 / 627)\end{array}$ & $\begin{array}{l}26.7 \% \\
(179 / 671)\end{array}$ & $0.96(0.85,1.07)$ & $0.79(0.58,1.09)$ & 0.15 \\
\hline Miscarriage rate & $16.0 \%(99 / 627)$ & $\begin{array}{l}14.7 \% \\
(97 / 671)\end{array}$ & $1.05(0.90,1.22)$ & $1.09(0.77,1.54)$ & 0.62 \\
\hline Live birth rate & $\begin{array}{l}39.5 \% \\
(511 / 1295)\end{array}$ & $\begin{array}{l}43.3 \% \\
(546 / 1261)\end{array}$ & $0.92(0.85 .1 .0)$ & $0.84(0.70,1.0)$ & 0.054 \\
\hline
\end{tabular}

The comparison of neonatal birthweight was similar between the two groups, both in singleton birth $(3366.4 \pm 536.0 \mathrm{~g}$ vs $3317.0 \pm 516.8 \mathrm{~g}, P>0.05)$ and twin birth $(2461.0 \pm 460.1 \mathrm{~g}$ vs $2472.6 \pm 472.2 \mathrm{~g}, P>$ 0.05) (Table 3). The proportion of pregnancy-related complications, the other neonatal outcomes including the prevalence of preterm birth and low birthweight, were similar between the two treatment groups $(P>0.05)$. 
Table 3

The neonatal outcome of artificial FET cycles using strengthened luteal phase support

\begin{tabular}{|c|c|c|c|}
\hline Characteristics & $\begin{array}{l}\text { Low } P+\text { strengthened LPS } \\
(n=511)\end{array}$ & $\begin{array}{l}\text { normal } P+\text { routine LPS } \\
(n=546)\end{array}$ & $P$ value \\
\hline Singletons & 363 & 412 & \\
\hline Newborn gender & & & 0.342 \\
\hline Female & 182 & 192 & \\
\hline Male & 181 & 220 & \\
\hline Birthweight (g) & $3366.4 \pm 536.0$ & $3317.0 \pm 516.7$ & 0.193 \\
\hline Gestation age (weeks) & $38.5 \pm 1.7$ & $38.4 \pm 1.9$ & 0.060 \\
\hline Low birthweight (<2500 g) & $16(4.4 \%)$ & $18(4.4 \%)$ & 0.986 \\
\hline Macrosomia ( $\geq 4000 \mathrm{~g}$ ) & $38(10.5 \%)$ & $32(7.8 \%)$ & 0.195 \\
\hline Pregnancy-related complications & $16(4.4 \%)$ & $32(7.8 \%)$ & 0.052 \\
\hline Twins & $295^{\star}$ & 268 & \\
\hline Newborn gender & & & 0.563 \\
\hline Female & 137 & 131 & \\
\hline Male & 158 & 137 & \\
\hline Birthweight (g) & $2461.0 \pm 460.1$ & $2472.6 \pm 472.2$ & 0.833 \\
\hline Gestation age (weeks) & $35.6 \pm 2.4$ & $35.5 \pm 2.5$ & 0.087 \\
\hline Very low birthweight $(<1500 \mathrm{~g})$ & $16(5.4 \%)$ & $14(5.2 \%)$ & 0.891 \\
\hline Low birthweight $(<2500 \mathrm{~g})$ & $116(39.3 \%)$ & $100(37.3 \%)$ & 0.552 \\
\hline Pregnancy-related complications & $25(16.9 \%)$ & $31(23.1 \%)$ & 0.212 \\
\hline
\end{tabular}

\section{Low serum P on the FET day was a risk factor for the chance of pregnancy}

The risk factors associated with pregnancy outcomes were explored by logistic regression analysis (Table 4). When the clinical pregnancy was chosen as the dependent factor, and age, BMI (categorical variable), number of embryos transferred, embryo stage, infertility causes and serum $P$ levels (categorical variable) were chosen as independent factors, the variants of age, the number and stage of embryos, infertility causes and P levels on the FET day were found to be significant independent prognosticators $(P<0.05)$. The age and number of transferred embryos had negatively influential for the pregnancy 
outcome, the infertility causes of PCOS and male factor had higher chance of pregnancy than the tubal factor in this study $(P<0.05)$. The low $P$ on the FET day $(P<10.0 \mathrm{ng} / \mathrm{ml})$, in the context of strengthened LPS, still decreased the chance of clinical pregnancy by $19 \%$ after adjusting confounding factors.

Table 4

The independent predictors of pregnancy outcomes in artificial FET cycles by logistic regression analysis

\begin{tabular}{|c|c|c|c|c|c|c|c|c|}
\hline \multirow[b]{3}{*}{ Female age } & \multicolumn{4}{|c|}{ Clinical pregnancy } & \multicolumn{4}{|c|}{ Live birth } \\
\hline & \multirow{2}{*}{$\begin{array}{l}\mathrm{RR} \\
0.96\end{array}$} & \multicolumn{2}{|c|}{$95 \% \mathrm{Cl}$} & \multirow{2}{*}{$\begin{array}{l}\text { P value } \\
0.00\end{array}$} & \multirow{2}{*}{$\begin{array}{l}\mathrm{RR} \\
0.96\end{array}$} & \multicolumn{2}{|c|}{$95 \% \mathrm{Cl}$} & \multirow{2}{*}{$\begin{array}{l}\text { P value } \\
0.00\end{array}$} \\
\hline & & 0.94 & 0.99 & & & 0.93 & 0.98 & \\
\hline Infertility duration & 1.00 & 0.96 & 1.03 & 0.93 & 0.99 & 0.95 & 1.02 & 0.42 \\
\hline Basal FSH value & 0.94 & 0.88 & 1.00 & 0.05 & 0.94 & 0.88 & 1.00 & 0.06 \\
\hline Antral follicle counts & 1.01 & 0.99 & 1.02 & 0.46 & 1.00 & 0.99 & 1.01 & 0.95 \\
\hline Embryo numbers ${ }^{a}$ & 1.92 & 1.52 & 2.43 & 0.00 & 1.80 & 1.42 & 2.29 & 0.00 \\
\hline Embryo stage $^{b}$ & 1.69 & 1.32 & 2.17 & 0.00 & 1.52 & 1.19 & 1.95 & 0.00 \\
\hline Serum $P$ on FET day ${ }^{c}$ & 0.81 & 0.68 & 0.96 & 0.02 & 0.84 & 0.70 & 1.00 & 0.05 \\
\hline $\mathrm{BMI}^{\mathrm{d}}$ & & & & 0.77 & & & & 0.81 \\
\hline Underweight & 0.86 & 0.65 & 1.15 & 0.30 & 0.93 & 0.70 & 1.24 & 0.62 \\
\hline Overweight & 1.00 & 0.81 & 1.24 & 0.97 & 0.91 & 0.74 & 1.13 & 0.40 \\
\hline Obesity & 0.99 & 0.67 & 1.47 & 0.97 & 1.04 & 0.71 & 1.54 & 0.83 \\
\hline Infertility causes ${ }^{e}$ & & & & 0.01 & & & & 0.15 \\
\hline PCOS & 1.55 & 1.18 & 2.03 & 0.00 & 1.26 & 0.96 & 1.64 & 0.09 \\
\hline Male & 1.41 & 1.04 & 1.92 & 0.03 & 1.38 & 1.02 & 1.87 & 0.04 \\
\hline Endometriosis & 0.86 & 0.48 & 1.53 & 0.61 & 1.06 & 0.59 & 1.89 & 0.85 \\
\hline Other & 1.08 & 0.83 & 1.40 & 0.56 & 1.21 & 0.93 & 1.57 & 0.16 \\
\hline
\end{tabular}

The multinomial logistic analysis, done to predict live birth rate, showed that only age, number and stage of embryos transferred were significantly related with live birth rate $(P<0.05)$. Low serum $P$ values on the FET day slightly reduced the live birth rate but did not reach the significance (aRR $0.84,95 \% \mathrm{Cl} 0.70-1.0)$. 


\section{Discussion}

Clinicians frequently preferred the artificial endometrial preparation for its advantage of easier programming of embryo transfer [3]. The increasing number of artificial cycles raises the question of the serum $P$ levels required to optimize the pregnancy outcome. In this large-sample retrospective study, we investigated the contribution of strengthened LPS for the pregnancy outcome in patients with low serum $\mathrm{P}$ on the FET day in artificial cycles. The strengthened LPS for the section of patients produced $39.5 \%$ live birth in the groups of low serum P, a slightly lower (3.8\%) than the groups with normal serum P levels and usage of routine LPS.

The principles for choosing LPS include of the minimum effective dose, good safety and tolerability [12]. This is an open question with many alternative answers, and the heterogeneous applications of the dose and routes make it difficult to compare LPS in different studies $[3,13]$. The pregnancy outcomes, especially live birth rate, become the endpoint of evaluating the effects of LPS in artificial FET cycles. Vaginal administration was the first choice of doctors, used alone or in combination with oral or intramuscular injection in a recent large survey [14]. In our center, the most popular regimen of LPS was using oral dydrogesterone $20 \mathrm{mg}$ twice daily and vaginal micronized P $200 \mathrm{mg}$ twice daily in artificial cycles. In this context, serum P level was a surrogate marker reflecting the systematic absorption extent of vaginal $\mathrm{P}$ administration. It might be interfered by individual variability, such as $\mathrm{BMI}$, mucus surface area, amount of cervical mucus and the difference of vaginal microbiome [4]. Thus, a marked interindividual difference of serum $P$ concentrations on the luteal phase was present despite the same dose of vaginal $P$ administration, the possibility of LPS insufficiency by vaginal route can not be excluded for the section of patients with low serum $P$ concentration in artificial cycles. The previous report compared three arms in artificial cycles using a randomized control trial (vaginal $200 \mathrm{mg}$ twice daily, im P $50 \mathrm{mg}$ daily only, vaginal $200 \mathrm{mg}$ twice daily + im P $50 \mathrm{mg}$ every third day), vaginal P only group was found a significantly lower ongoing pregnancy rate compared the other two groups ( $31 \%$ vs $50 \%$ vs $47 \%$ ), and the trial did not continue after inter analysis for the higher proportion of biochemical pregnancy loss and miscarriage [15]. Unfortunately, no data on serum progesterone levels in the three groups were available from that study. The low serum $P$ levels on the FET day in artificial cycles using vaginal route were previously reported to be associated with poorer reproductive outcomes, the cutoff value was varied in previous reports $(5.0-12.0 \mathrm{ng} / \mathrm{ml})[5-8]$. In this study, the cutoff value was set as $10.0 \mathrm{ng} / \mathrm{ml}$.

In this study, the strengthened $P$ replacement was a protective approach, with attempting to mitigate the effects of low serum P4 that fell below this threshold. For the topic, the ideal control was using routine LPS for the patients with low serum P on the FET day, but our previous tendency of doctors was to add P to avoid the possible harm and maximize the patients' benefits in a conservative view. Limited by the realworld data in our clinic, we converted to use the population of normal serum P and routine LPS as controls, the current data showed slight lower pregnant outcomes of strengthened LPS in the lower P group. Although our study can not distinguish the difference origin from the harm caused by lower serum $P$ or the benefits of additional $P$, the current comparison data still provided some meaningful information. Firstly, the patients of low serum P and strengthened LPS showed a slightly lower clinical pregnancy and 
live birth rate compared with the normal control, it decreased the chance of clinical pregnancy by $19 \%$ after adjusting confounding factors. Similar results were reported in Alsbjerg et al [16], serum P levels below $11.0 \mathrm{ng} / \mathrm{ml}(35 \mathrm{nmol} / \mathrm{l})$ decreased the chance of ongoing pregnancy with a risk reduction of $14 \%$ in hormone replacement therapy FET cycles. Using the logistic regression model in this study, the low serum $\mathrm{P}$ level, as categorical variable, was a risk factor for the chance of pregnancy in artificial endometrial preparation cycles, which indicated the suboptimal condition in this section of patients with low serum $P$.

Secondly, the pregnancy outcome of the groups of low P and strengthened LPS was an acceptable result, clinical pregnancy rate $(48.4 \%)$ and live birth rate (39.5\%) appeared reasonable, the similar proportion of biochemical pregnancy loss and miscarriage also approved the efficacy of strengthened LPS. As such, even though serum $P$ has been inadequate on the FET day, this was potentially remedied by additional $P$ administration, reinforcing intervention might still be possible beyond the day of transfer. The results were in coincide with the recent report of Volovsky et al, $\mathrm{P}$ replacement enhanced the pregnancy outcome if the $P$ on the FET day was lower than $8.0 \mathrm{ng} / \mathrm{ml}$ [8]. In a recent study of Polats et al., the intramuscular $P$ supplementation every third day did not increase the ongoing pregnancy rate compared with vaginal $P$ only in vitrified blastocyst transfer cycles (48.3\% vs $51.8 \%$ ). However, the patients with serum $\mathrm{P}$ less than $8.75 \mathrm{ng} / \mathrm{ml}$ in vaginal P only group had a numerically lower ongoing pregnancy rate ( $28.6 \% \mathrm{vs} 46.6 \%)$, but did not reach the statistically significant difference [9].

The current study also had several strengths. The vaginal P administration achieved higher endometrial tissue concentrations and lower systemic exposures than observed after intramuscular injection, and the dose-effect relationship was not obvious in the same route of $P$ administration [4], so the combination of two or three routes, rather than increasing dose of single route, is a reasonable choice to meet the requirement of endometrial transfection in artificial cycles. Multiple routes of $\mathrm{P}$ administration provided sufficient luteal support in artificial FET cycles. The secondary strength was the large cohort size, it had sufficient power to answer the question whether it was beneficial of strengthened LPS to overcome the possible negative influence in the cycles with low serum $P$ on the FET day. All cycle data were derived from a single institution, where practice consistency can be assured.

Our study was limited by its retrospective design. In this context, we screened the database with strict inclusion criteria, analysis was restricted to first artificial cycles and normal ovarian reserve, and a number of potential confounders were well controlled in the current study. Additionally, the vast majority of patients in the present study were young and normal ovarian reserve, so the extrapolation to an unselected population needs to be validated.

In the previous report of Yovich et al., maternal age, embryo quality and mid-luteal serum progesterone levels were listed as three important factors governing the implantation rates for artificial FET cycles [17]. In this study, serum P levels on the FET day, as a categorical variable, were found to be a significant independent prognosticator of clinical pregnancy, while it did not reach the statistically significance for live birth rate. The explanation of the results should be cautious. Strengthen LPS might be useful for the 
patients with low serum $\mathrm{P}$ levels on the FET day in artificial cycles, further study is need to perform randomized controlled trials to evaluate the individualization of $\mathrm{P}$ dosage.

\section{Conclusions}

In summary, our study confirmed serum $\mathrm{P}$ levels on the FET day might be one of risk factors for the chances of pregnancy in artificial cycles, and careful monitoring of serum $\mathrm{P}$ concentration was warranted. The strengthened LPS might help to have a reasonable pregnancy outcome in the section of low $\mathrm{P}$ on the FET day in artificial cycles, although it was a slightly lower than the groups with normal serum $P$ levels on the FET day and usage of routine LPS. Our study added new information to the fields of luteal phase support and further studies should explore $\mathrm{P}$ administration to optimize concentrations for individual women to improve pregnancy outcomes.

\section{Declarations}

\section{Ethical Approval and consent to participate}

Human Ethics Committee approval for the retrospective trial of frozen embryo transfer cycles came from the Institutional Review Board (IRB) of the Shanghai Ninth People's Hospital on August 20, 2020 (Number: SH9H-2020-T268-1).

\section{Consent for publication}

All patients consent the data used for research and publication

\section{Availability of supporting data}

The data is not publicly shared and please contact author for data requests.

\section{Competing interests}

The authors have nothing to declare.

\section{Funding}

The study was funded by The National Natural Science Foundation of China (81671520) the Natural Science Foundation of Shanghai (1841196400 and 19411961100).

\section{Authors' contributions}

QJC, QQH and LHS supervised the entire study, including procedures, conception, design, and completion. HYG, JY and HJY contributed to the data analysis and manuscript drafting. All authors participated in the ultimate interpretation of the study data and in revisions to the article. The authors have nothing to declare. 
Acknowledgments

We gratefully acknowledge all staff of the department of assisted reproduction in Shanghai Ninth People's Hospital for their support and cooperation.

\section{References}

1. Nawroth F, Ludwig M. What is the 'ideal' duration of progesterone supplementation before the transfer of cryopreserved-thawed embryos in estrogen/progesterone replacement protocols?. Hum Reprod. 2005;20(5):1127-1134.

2. Boynukalin FK, Gultomruk M, Turgut E, et al. Measuring the serum progesterone level on the day of transfer can be an additional tool to maximize ongoing pregnancies in single euploid frozen blastocyst transfers. Reprod Biol Endocrinol. 2019;17(1):102

3. van der Linden M, Buckingham K, Farquhar C, Kremer JA, Metwally M. Luteal phase support for assisted reproduction cycles. Cochrane Database Syst Rev. 2015;2015(7):CD009154

4. Paulson RJ, Collins MG, Yankov VI. Progesterone pharmacokinetics and pharmacodynamics with 3 dosages and 2 regimens of an effervescent micronized progesterone vaginal insert. J Clin Endocrinol Metab. 2014;99(11):4241-4249

5. Brady PC, Kaser DJ, Ginsburg ES, et al. Serum progesterone concentration on day of embryo transfer in donor oocyte cycles. J Assist Reprod Genet. 2014;31(5):569-575

6. Labarta E, Mariani G, Holtmann N, Celada P, Remohí J, Bosch E. Low serum progesterone on the day of embryo transfer is associated with a diminished ongoing pregnancy rate in oocyte donation cycles after artificial endometrial preparation: a prospective study. Hum Reprod. 2017;32(12):24372442.

7. Gaggiotti-Marre S, Martinez F, Coll L, et al. Low serum progesterone the day prior to frozen embryo transfer of euploid embryos is associated with significant reduction in live birth rates. Gynecol Endocrinol. 2019;35(5):439-442.

8. Volovsky M, Pakes C, Rozen G, Polyakov A. Do serum progesterone levels on day of embryo transfer influence pregnancy outcomes in artificial frozen-thaw cycles? J Assist Reprod Genet. 2020 May;37(5):1129-1135.

9. Polat M, Mumusoglu S, Bozdag G, Ozbek IY, Humaidan P, Yarali H. Addition of intramuscular progesterone to vaginal progesterone in hormone replacement therapy in vitrified-warmed blastocyst transfer cycles. Reprod Biomed Online. 2020;40(6):812-818.

10. Gardner DK, Lane M, Schoolcraft WB. Physiology and culture of the human blastocyst. J Reprod Immunol. 2002;55(1-2):85-100.

11. Kuwayama M, Vajta G, Kato O, Leibo SP. Highly efficient vitrification method for cryopreservation of human oocytes. Reprod BioMed Online. 2005;11(3):300-8

12. Yanushpolsky EH. Luteal phase support in in vitro fertilization. Semin Reprod Med. 2015;33(2):118127

Page 14/16 
13. Tavaniotou A, Smitz J, Bourgain C, Devroey P. Comparison between different routes of progesterone administration as luteal phase support in infertility treatments. Hum Reprod Update. 2000 MarApr;6(2):139-48

14. Di Guardo F, Midassi H, Racca A, Tournaye H, De Vos M, Blockeel C. Luteal Phase Support in IVF: Comparison Between Evidence-Based Medicine and Real-Life Practices. Front. Endocrinol.2020;11:500

15. Devine K, Richter KS, Widra EA, McKeeby JL. Vitrified blastocyst transfer cycles with the use of only vaginal progesterone replacement with Endometrin have inferior ongoing pregnancy rates: results from the planned interim analysis of a three-arm randomized controlled noninferiority trial. Fertil Steril. 2018;109(2):266-275.

16. Alsbjerg B, Thomsen L, Elbaek HO, Laursen R, Povlsen BB, Haahr T, Humaidan P. Progesterone levels on pregnancy test day after hormone replacement therapy-cryopreserved embryo transfer cycles and related reproductive outcomes. Reprod Biomed Online. 2018 Nov;37(5):641-647

17. Yovich JL, Conceicao JL, Stanger JD, Hinchliffe PM, Keane KN. Mid-luteal serum progesterone concentrations govern implantation rates for cryopreserved embryo transfers conducted under hormone replacement. Reprod Biomed Online. 2015;31(2):180-191

\section{Figures}




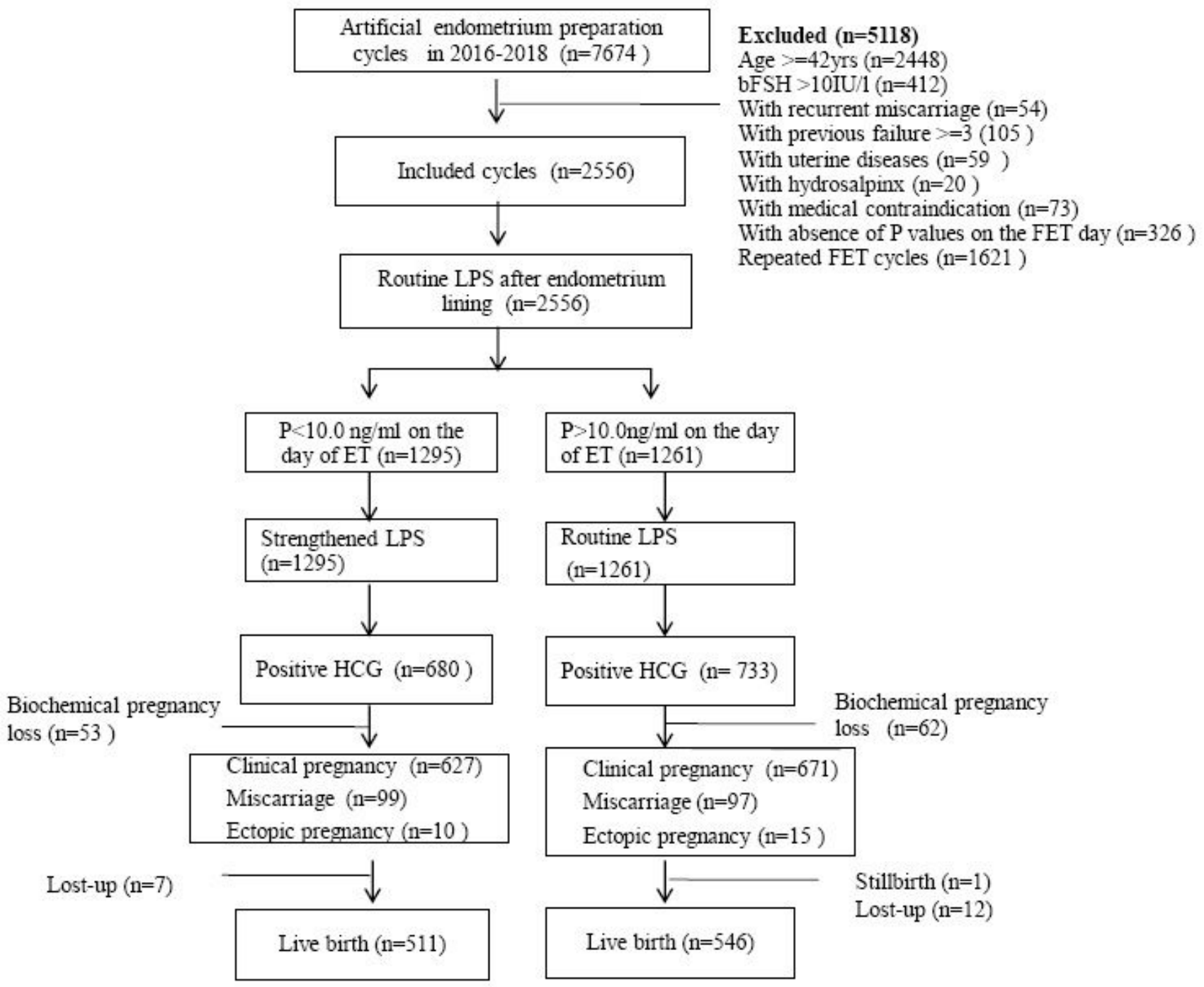

Figure 1

The flowchart of the retrospective cohort trial. 